\title{
Ultrasound for Critical Care Physicians: Dyspnea
}

A 62 year old man with metastatic melanoma presented to the Emergency Department with dyspnea, hypoxemia, and tachycardia. A bedside ultrasonography was performed (Figure 1).

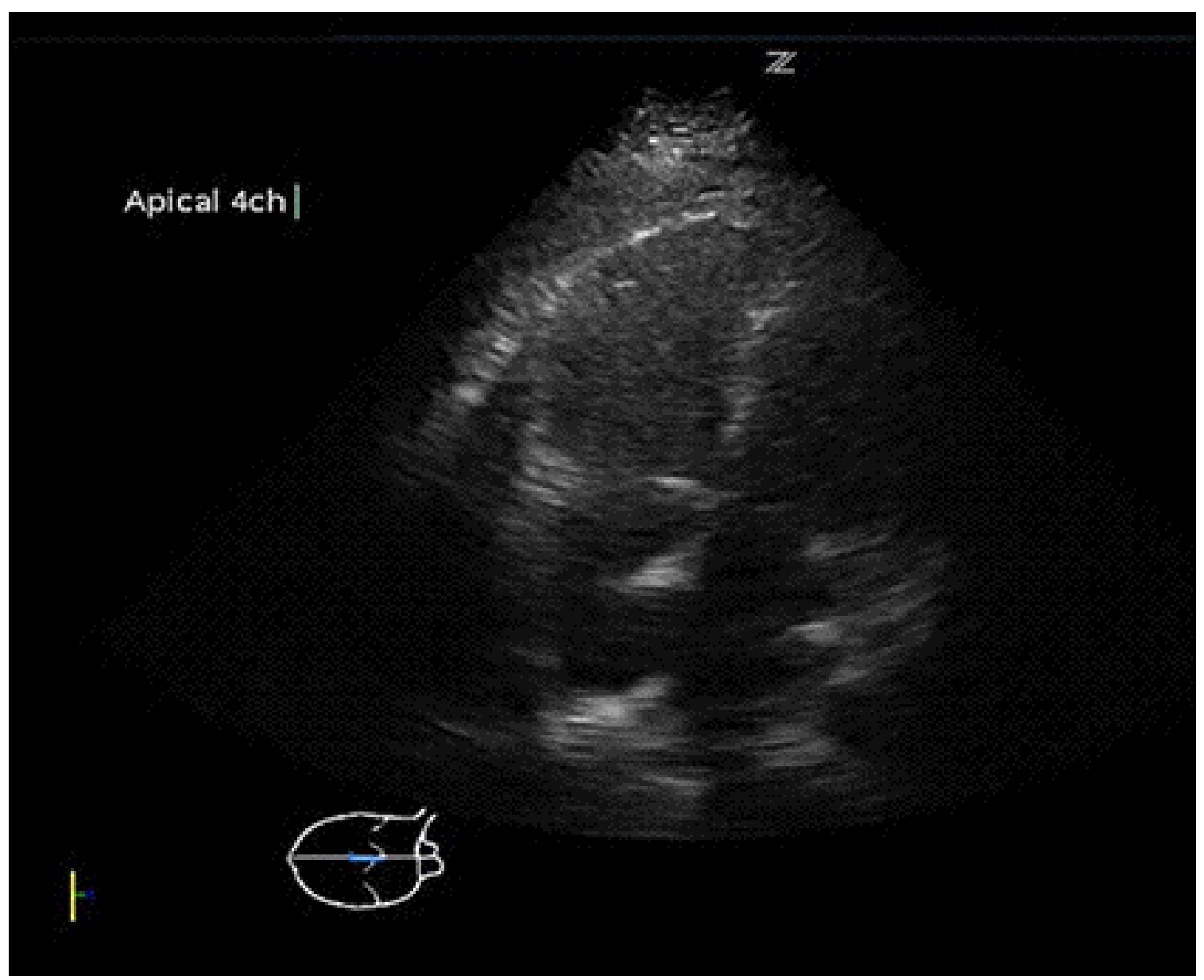

Figure 1. Static view of the beside ultrasonography

Which of the following diagnosis is most compatible with the ultrasound findings?

1. Cardiac thrombus

2. Cardiogenic shock

3. Mitral stenosis

4. Pericardial effusion

5. Pulmonary embolism 


\section{Correct! \\ 5. Pulmonary embolus}

This is a good example of severe right ventricular dysfunction based on tricuspid annular plane systolic excursion (TAPSE). Normally the tricuspid annular plane moves over 1.6 centimeters (1). This excursion is decreased with high right-sided pressures. The clinical situation with the ultrasound findings of high right-sided pressure is most compatible with pulmonary embolism.

TAPSE is most easily measured with M mode (Figure 2).

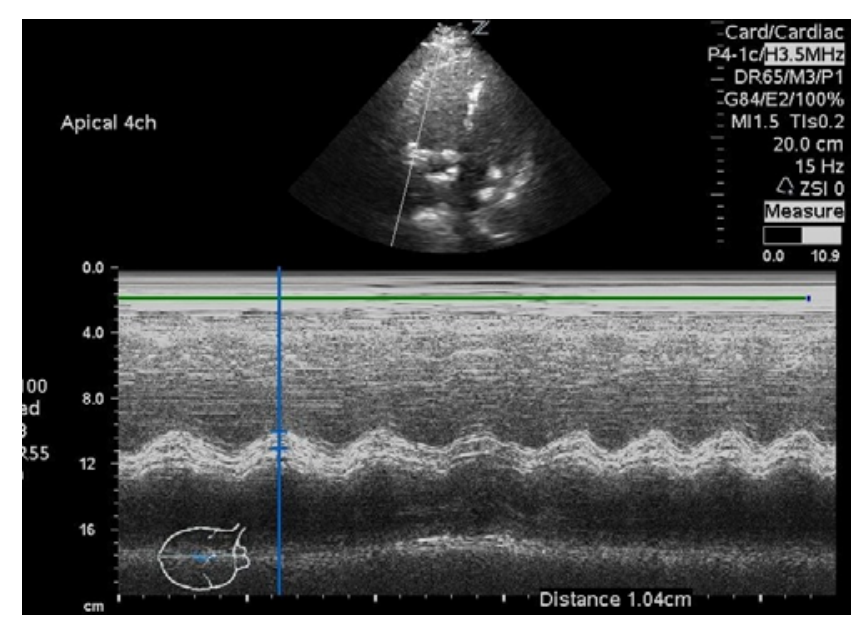

Figure 2. M mode with the cursor placed at the free wall of the tricuspid annulus. TAPSE is the distance of tricuspid annular movement between end-diastole to end- systole (the distance between the two horizontal blue lines), in this case about 1.04 $\mathrm{cm}$.

As further evidence a dilated, non-collapsible inferior vena cava (IVC) was detected on ultrasonography to support the high right-sided pressure findings (Figure 3).

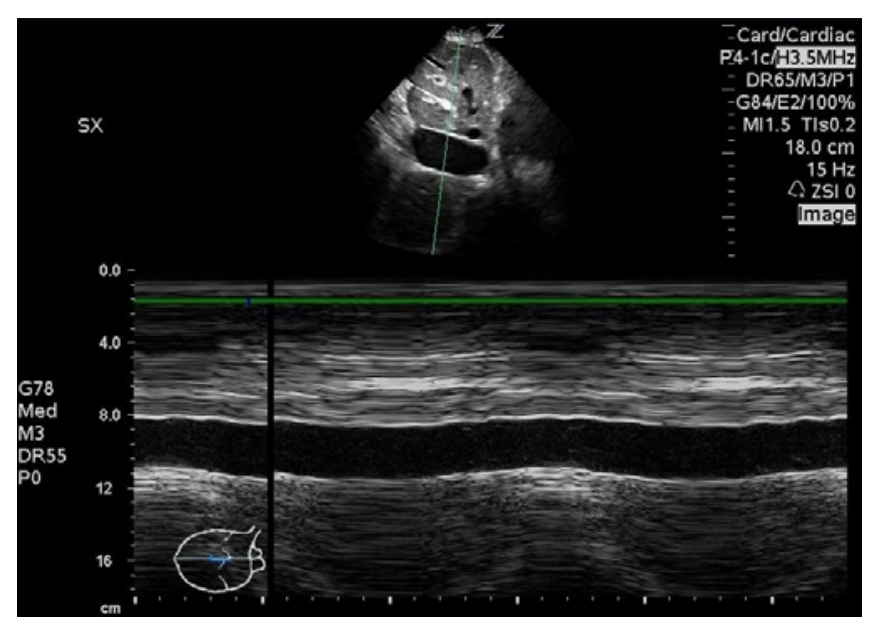

Figure 3. Static ultrasonography showing a dilated IVC (about $3.7 \mathrm{~cm}$, normal $<2.5 \mathrm{~cm}$ ). 
The patient later proved to have a pulmonary embolism by CT angiography as the cause of his acute RV pressure overload.

Matthew J. Thompson, MD

Department of Emergency Medicine

University of Arizona

Tucson, AZ

\section{Reference}

1. Rudski LG, Lai WW, Afilalo J, Hua L, Handschumacher MD,Chandrasekaran K, Solomon SD, Louie EK, Schiller NB. Guidelines for the echocardiographic assessment of the right heart in adults: a report from the American Society of Echocardiography endorsed by the European Association of Echocardiography, a registered branch of the European Society of Cardiology, and the Canadian Society of Echocardiography. J Am Soc Echocardiogr. 2010;23(7):685-713. [CrossRef] [PubMed] 